1Case reports

\title{
2Rapid Efficacy of Gemtuzumab Ozogamicin in 3Refractory AML Patients with Organ Dysfunctions
}

\author{
4Daniil Zaytsev *, Larisa Girshova, Vladimir Ivanov, Irina Budaeva, Dmitri Motorin, Renat Badaev, \\ 5Julia Mirolubova, Tamara Chitanava, Ekaterina Zaykova, Julia Alexeeva, Andrey Zaritskey \\ 6 Almazov National Medical Research Centre, 2 Akkuratova street, St. Petersburg, Russia, 197341. \\ 7 * Correspondence: Daniil Vladislavovich Zaytsev, hematologist, Almazov National Medical Research Centre, \\ 82 Akkuratova street, St. Petersburg, Russia, 197341. Tel..+7-981-727-16-74, e-mail: zaicev daniil@mail.ru.
}

9

10 Abstract: Objectives: To demonstrate the efficacy of Gemtuzumab ozogamicin in refractory 11AML patients with organ dysfunctions and poor performance status.

12 Three refractory AML patients with are described. One of them was pretreated by intensive 13chemotherapy, two other patients progressed during Azacitidine treatment. WHO performance 14status III . Two patients had respiratory failure grade 2, the other one suffered from acute kidney 15 insufficiency. Two patients were highly febrile with elevated CRP level.

16 Gemtuzumab ozogamicin administration was performed in three patients followed by further 17 switch to Gemtuzumab ozogamicin + Azacitidine or " $7+3$ " treatment. Results: Gemtuzumab 18ozogamicin administration resulted in abrupt fever cessation in two febrile patients simultaneously 19 with CRP level decrease and fast gradual resolution of respiratory failure. Recovery of kidney 20 function was noticed in patient with renal insufficiency. WHO performance status have elevated in 21 all three patients. No adverse effects grade II-III were noticed. Further treatment made two patients 22eligible for intensive chemotherapy, one patient was transplanted, patient with kidney failure 23obtained complete remission. Conclusions: Gemtuzumab ozogamicin therapy appeared to be safe 24and highly efficacious in relapsed/refractory AML patients with organ dysfunctions and poor 25performance status.

26 Keywords: acute myeloid leukemia; patients with organ dysfunction; gemtuzumab ozogamicin 27

\section{Introduction}

29 Patients with acute myeloid leukemia (AML) comprise the cohort of patients at a higher risk for 30life-threatening complications and ICU admission for intensive monitoring and treatment due to the 31 severity of the disease, hospital-acquired infections and intensive chemotherapy regimens used. $32[1,2]$.

33 Relapsed and refractory AML (10-40\% of AML) represents the most common group of AML 34 patients with organ dysfunctions and poor outcomes [3].

35 Early ICU admission improves survival and may be appropriate in patients with incipient 36organ dysfunction [2], including patients with kidney dysfunction for acute kidney injury 37prevention[4].

38 Moreover, cancer chemotherapy along with life-sustaining therapies in critically ill patients 39 with cancer-related organ dysfunctions is feasible and associated with a meaningful survival benefit 40in selected patients [4].

41 The most common complication of refractory AML salvage therapy is pneumonia caused by 42different infectious agents[5]. 
43 Thorough examination of pulmonary infiltrates occuring during treatment some uncertainties 44regarding their origin still remain [6].

45 Approximately $34-40 \%$ occurred during the disease and treatment are of infectious origin, $34 \%$ 46 are noninfectious, and in $24 \%$ the cause [6]. Lung infiltrates is also described $[7,8]$.

47 Hypoxemic acute respiratory failure with pulmonary infiltrates is one of the major 48life-threatening complications in patients with hematological malignancies. Management of these 49patients is complex, and is associated with poor outcomes [4].

50 Furthermore, sepsis also remains to be one of the independent prognostic risk factor for 51patients death [9]. Recent studies have revealed sepsis is an extremely complicated 52immunopathological process [10], and it has been shown that Il-6 blockade can prevent 53inflammatory-induced organ damage [11]. This direction could become a promising approach to 54 sepsis therapy.

55 Major concerns related to administration of chemotherapy in the ICU lie in the practical issue of 56team experience [4]. In our opinion, patients with organ dysfunctions deserve special attention and a 57 searching for non-toxic chemotherapy regimens.

58 Low toxicity of Gemtuzumab ozogamicin (GO) seems to provide a new promising option for 59highly compromised patients treatment. Amadori et al. reported the results of GIMEMA trial of GO 60versus best supportive care in the treatment of unfit for intensive chemotherapy patients in a 61 front-line setting [12]. The toxicity of GO was comparable to best supportive care, whereas 62 statistically significant increase of overall survival was shown in the GO arm. Moreover, GO has 63been shown to be an efficacious treatment in relapse/refractory AML patients [13,14]. However, 64 significant organ dysfunctions were the exlusion criteria in these trials. To the best of our knowledge, 65 data of GO use AML patients with organ function are lacking.

66 Here, we describe three patient with organ failures benefited from GO use. All of them had 67uncontrolled leukemic overgrowth.

\section{Clinical cases}

69 Three male patients with refractory CD 33+ AML, who had had organ dysfunction and poor $70 \mathrm{WHO}$ status performance at the moment of the therapy initiation, have been included in our clinical 71 observation.

72 Clinical data and the results of the therapy of patient G.A. is presented below. Clinical data and 73results of the therapy of patients A.D. and L.Ja. are summarised in table 1 (see table 1) 74

75 35-year-old male patient with primary chemorefractory acute myeloid leukemia with 76maturation, intermediate risk group ELN2017 . Bone marrow was hypercellular with 33,5\% of 77 blast cells. Cytogenetic analysis revealed a trisomy 8 . No molecular abnormalities were detected .

78 Two induction cycles of «7+3» regimen without remission were followed by therapy in 79 "FLAG" regimen. The latter therapy was complicated with a febrile neutropenia, the bloodstream 80infection associated with Ralstonia pickettii and polyresistant Klebsiella pneumoniae, an activation 81 of CMV infection. Antibacterial medications according to in vitro sensitivity and empirical 82 animycotic therapy was started on day 8 of "FLAG". Gancyclovir was added on day 9 of "FLAG". 83Four consecutive switches of antibacterial therapy and two switches of antifungal therapy were 84 made. The latest modification of antifungal therapy was made on day 13 and antibacterial therapy $85 \mathrm{on}$ the following day. During all the period of antibacterial/antifungal therapy the patient condition 86 continued to get worse. The patient had experienced high fever, CRP increased up to $295 \mathrm{mg} / \mathrm{l}$ (Fig. 871). WHO performance status of 3 had been assessed. Eventually, the patient had progressed to acute 88respiratory failure grade 2 with progressive increasing of dyspnea and worsened isolated 89hypoxemia (Fig. 1). 


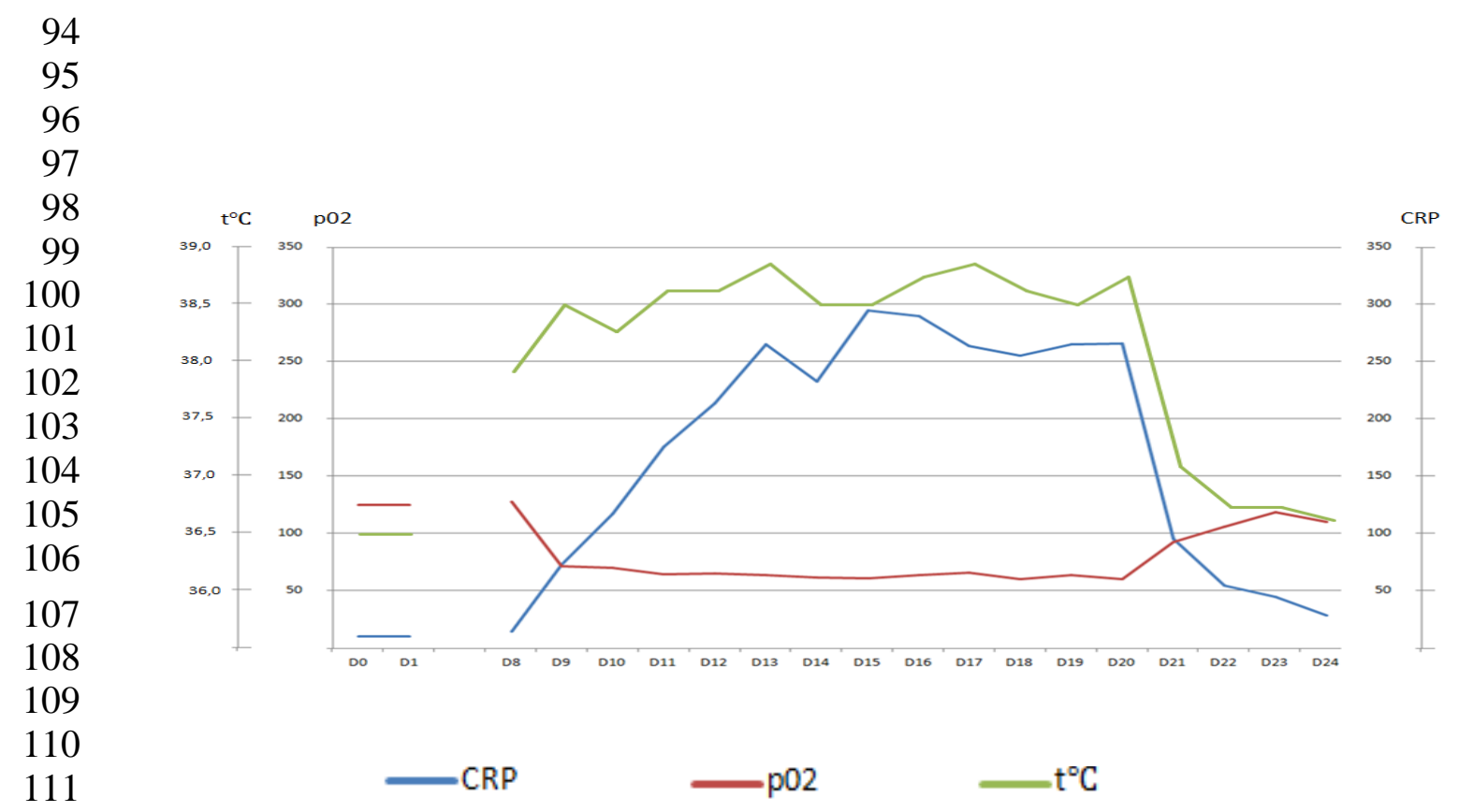

112

113

(CRP, PO2, temperature before «GO")

\section{Figure 1.}

115 Increaseing in size lung infiltrates were revealed on serial CT scans.

116 A chest CT scan on day 18 of "FLAG" showed massive infiltrates in the basal segments of the 117lower lobes in both lung fields with dense peribronchial lesions, multiple small interstitial lesions in 11851, S2-3, S6, S8 on both sides of the lungs (Fig.2).

119

120

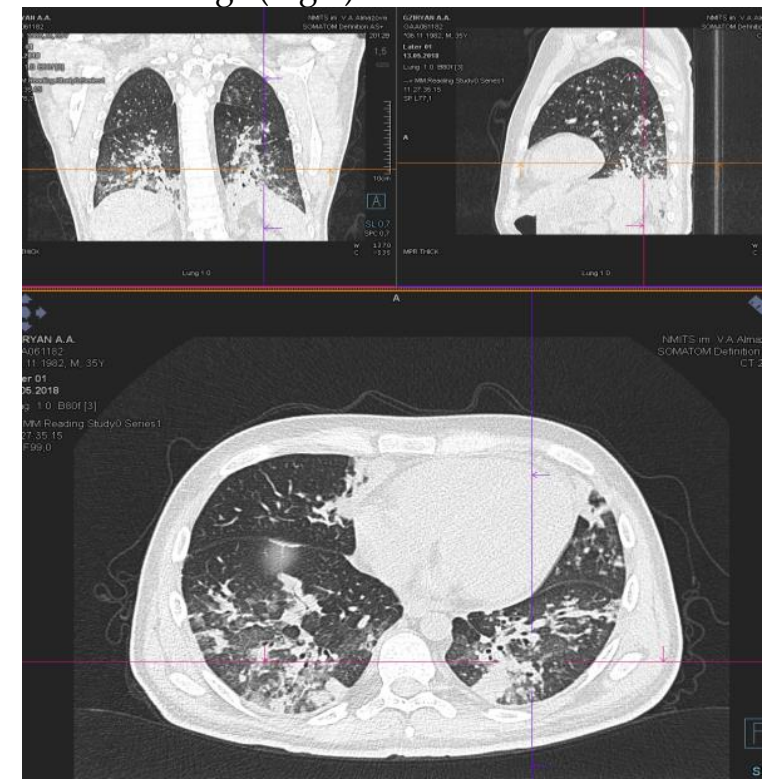

(CT chest scan on day 18 of "FLAG")

\section{$121 \quad$ Figure 2.}

122 Repeated broncho-alveolar lavages ware negative for any pathogens, galactomannan was 123negative.

124 Marrow blast cells reached $91.6 \%$ with $62.2 \%$ of CD33 positive cells on day 19 of "FLAG".

125 GO therapy was started on day 20 of "FLAG" therapy (Day I of GO).

126 During Day I after GO administration blood gas normalization with acute respiratory failure 127recovery was achieved. Apyrexia was noticed on Day II after GO infusion (fig.3). 
128 CRP started to decline and fell down to $29 \mathrm{mg} / \mathrm{l}$ on Day V after Gem. (Fig.3).

129

130

131

132

133

134

135

136

137

138

139

140

141

142

143

144

145

146

147

148

149

150

151

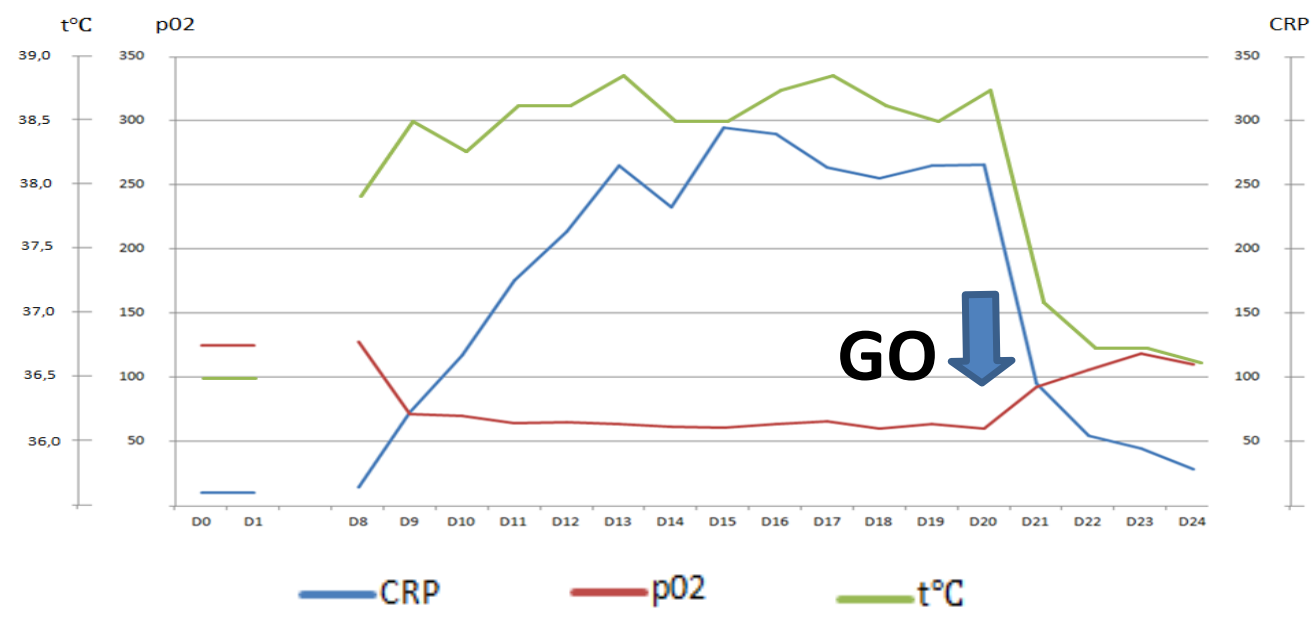

(CRP, PO2, temperature after «GO")

Figure 3.

152infiltrates in the size and density (Fig.4).

WHO performance status improved to 2 grade.

A chest CT scan on Day III of the GO therapy showed a significant regression of pulmonary

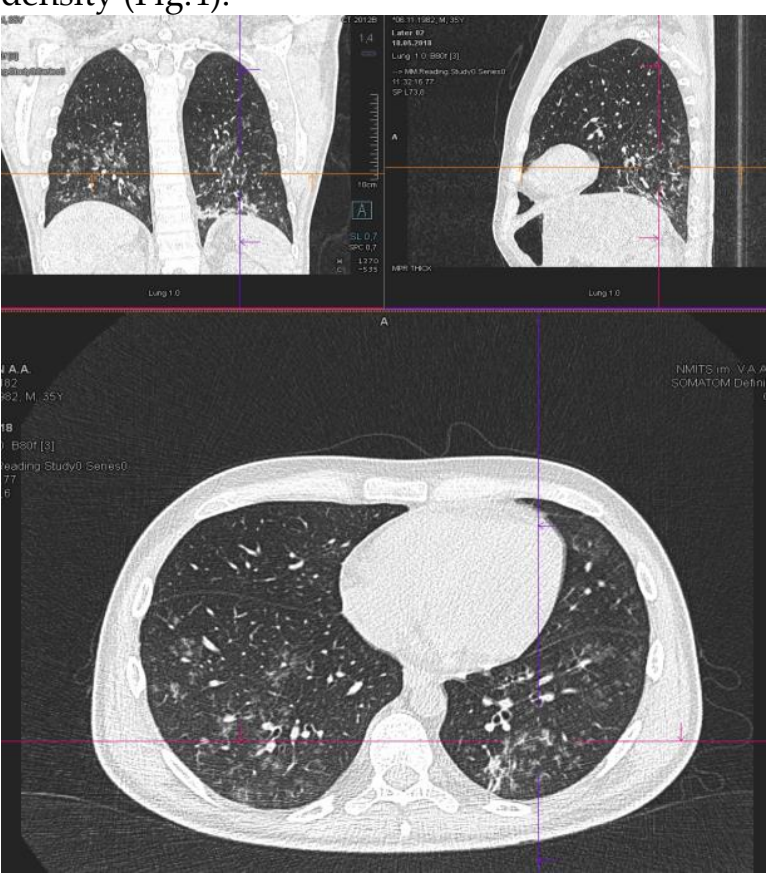

(CT chest scan on day III of "GO")

\section{$155 \quad$ Figure 4.}

156 Therapy was augmented by «Gemtuzumab ozogamicin+Azacitidine» regimen (GO 3mg/m2 157day 8, Azacitidine $50 \mathrm{mg} / \mathrm{m} 2$ days 1-7), which was started on Day V after GO. The patient was treated 158 by the two consecutive cycles of the therapy in "Gemtuzumab ozogamicin+Azacitidine» regimen. 159 No non-hematological adverse effects grade 3-4 were observed. Antibacterial therapy was 
160 gradually deescalated and stopped. Marrow blast cells count in the marrow gradually decreased. 161Best response after the $2^{\text {nd }}$ cycle of the therapy was morphologic free leukemia state 162(MLFS)achievement: blasts count 1,5\% without peripheral blood cells recovery (not shown)

163 The patient underwent allogeneic stem cell transplantation from a matched related donor with 164 complete remission with complete donor chimerism achievement (not shown).

165 166
Table 1. Clinical data and results of the therapy of patients A.D. and L.Ja. are summarised in the table

\begin{tabular}{|c|c|c|}
\hline $\begin{array}{l}\text { Sex } \\
\text { Age }\end{array}$ & $\begin{array}{c}\text { Male patient. } 74 \text { years } \\
\text { A.D. }\end{array}$ & $\begin{array}{c}\text { Male patient. } 54 \text { years } \\
\text { L.Ja }\end{array}$ \\
\hline Diagnosis & $\begin{array}{l}\text { AML without maturation (NOS, } \\
\text { WHO2016). Intermediate risk group } \\
\text { (ELN2017). Normal karyotype. } \\
\text { Primary refractory disease. }\end{array}$ & $\begin{array}{c}\text { AML with maturation (NOS, } \\
\text { WHO2016). add(21)(q22). } \\
\text { Intermediate risk group (ELN2017). } \\
\text { Primary refractory disease. }\end{array}$ \\
\hline Clinical data & $\begin{array}{l}\text { A patient with a progression disease } \\
\text { during the treatment by Azacitidine. } \\
\text { Increasing blast cells in blood and } \\
\text { marrow more than by } 50 \% \text { from } \\
\text { baseline after } 2 \text { cycles of Azacytidine } \\
\text { therapy. }\end{array}$ & $\begin{array}{l}\text { A patient with a progression disease } \\
\text { during the treatment by Azacitidine. } \\
\text { Increasing blast cells in blood and } \\
\text { marrow more than by } 50 \% \text { from } \\
\text { baseline after } 2 \text { cycles of Azacytidine } \\
\text { therapy. }\end{array}$ \\
\hline $\begin{array}{l}\text { Patient status } \\
\text { before } \\
\text { Gemtuzumab } \\
\text { ozogamicine } \\
\text { therapy } \\
\text { initiation }\end{array}$ & $\begin{array}{l}\text { WHO status performance of } 3 \text {. Marrow } \\
\text { blast cells } 88,6 \% \text {, peripheral blood blast } \\
\text { cells } 60 \% \text {, pancytopenia grade } 3-4 \text {. } \\
\text { CRP was slightly increased to } 20 \mathrm{mg} / \mathrm{l} \text {. } \\
\text { Acute kidney failure grade } 2 \text { with no } \\
\text { prior history of chronic kidney disease } \\
\text { or the use of a nephrotoxic agents. } \\
\text { Creatinine increasing up to } 2,8 \times U L N \\
\text { and GFR decline to } 15 \mathrm{ml} / \mathrm{min} \text {. }\end{array}$ & $\begin{array}{l}\text { WHO status performance of } 3 \text {. } \\
\text { Marrow blasts cells } 68 \% \text {. High fever } \\
\text { and elevated CRP level up to } 332 \mathrm{mg} / 1 \\
\text { with no response to escalated } \\
\text { antibiotics/antimycotics combination. } \\
\text { The patient had respiratory failure } \\
\text { grade } 2 \text { with massive bilateral } \\
\text { polysegmental lungs infiltrates } \\
\text { according to a chest CT scan. }\end{array}$ \\
\hline $\begin{array}{l}\text { Regimen of } \\
\text { therapy with } \\
\text { GO }\end{array}$ & $\begin{array}{c}\text { «GO } » 1 \text { cycle } \\
« \mathrm{GO}+\mathrm{Aza} » 1 \text { cycle }\end{array}$ & «GO » 1 cycle \\
\hline $\begin{array}{l}\text { Response to } \\
\text { the therapy }\end{array}$ & $\begin{array}{c}\text { WHO status performance improved to } \\
\text { grade } 2 .\end{array}$ & $\begin{array}{l}\text { WHO status performance improved to } \\
\text { grade } 2 \text {. Apyrexia was achieved on } \\
\text { day } 3 \text { of the GO therapy } \\
\text { CRP level started to drop on day } 1 \text { of } \\
\text { the therapy (CRP on day } 2-250 \mathrm{mg} / \mathrm{l} \text {, } \\
\text { on day } 7-60 \mathrm{mg} / \mathrm{l} \text { ) } \\
\text { A chest CT scan on the } 6^{\text {th }} \text { day of the } \\
\text { GO therapy showed a significant } \\
\text { regression of pulmonary infiltrates in } \\
\text { the size. } \\
\text { Day } 7 \text { marrow blast cells } 46 \% \text {. Thus } \\
\text { blast cells reduction was achieved on } \\
\text { day } 7 \text { after GO infusion. } \\
\text { The patient became eligible for chemo } \\
\text { intesification. On day } 12 \text { of the therapy } \\
\text { "7+3" was initiated }\end{array}$ \\
\hline
\end{tabular}


Day 14 marrow blast cells 16,1\%. Peripheral blood cells recovery was achieved on day 40 of the «GO+Aza» therapy. Day 40 the marrow blast cell $1 \%$. Thus complete remission with peripheral blood cells recovery was achieved.

\section{Discussion}

168 In three patients with a primary resistance to standard chemotherapy regimens ("FLAG" or 169Azacitidine), poor performance status and organ dysfunctions (respiratory failure, acute kidney 170injury ) GO monotherapy was chosen for the treatment. CD33blast cell positivity was obligatory 171 for including the patients in this treatment plan.

172 All the patients had leukemia progression. Patients(G.A., L. Ja.) with respiratory dysfunction 173 were resistant to preceding and ongoing antimicrobial and antiviral therapy.

174 They had persistent fever, increased CRP level, bilateral polysegmental lungs infiltrates with 175 symptoms of acute respiratory failure.

176 Following GO administration their arterial blood gases gradually improved over the first days 177 (patient G.A. on day I, patient L. Ja. on day II) . Apyrexia was achieved over the first three days after 178GO (patient G.A. on day II, patient L. Ja. on day III). CRP value started to decrease dramatically over 179the first day after GO infusion and continued to decline progressively. A repeated chest CT (In 180patient G.A. on day III, in patient L. Ja. on day VI) showed a partial regression of infiltrates after the 181 therapy.

182 Patient L. Ja. became eligible for chemo intesification and was switched to " $7+3$ " regimen with 183 insignificant bone marrow blast cell reduction (48\% blast cells)

184 In patient with acute kidney injury (A.D.)with no prior history of chronic kidney disease, use of 185 nephrotoxic agents or tumor lysis syndrome signs, creatinine started to decrease on day I after GO 186and returned to normal value on day VI.

187 Therefore, a rapid resolution of renal insufficiency on GO therapy (patient A.D. ) as well as 188 drastic decrease of infiltrative lung lesions ( Patients G.A. and L. Ja. ) could be presumably attributed 189 to anti-leukemic effect this medication. the overall incidence of extramedullary lesions reported in 190the literature ranging from $2.5 \%$ to $30 \%$ [15].

191 However, due to thrombocytopenia grade 4 with refractoriness to platelets transfusion organ 192 biopsy was not performed in all three patients.

193 At the next step, patients G.A. and L. Ja. were switched to combined Gemtuzumab ozogamicin 194treatment due to the ability of the latter to potentiate the efficacy of GO and overcome resistance 195 to GO [14, 16]. After two cycles of this regimen, morphologic free leukemia state was achieved in 196patient G.A. and complete remission with peripheral blood cells recovery in patient A.D..

197 As it is the response to mono GO or in combination with Azacitidine has been previously 198described in R/R AML patients even with extramedullary involvements $(17,18,19)$, although, 199nobody report the immediate response to Gem. Nevertheless, Mechanism of GO pharmacokinetics 200provides explanation for this prompt effect. GO rapidly binds to its receptor followed by immediate 201 internalization of cytostac-antibody complex leading to apoptosis of CD33 positive leukemia [20]

202 The alternative explanation of the rapid response to the GO therapy could result from its 203 significant immunomodulatory effect.

204 In a xenomodel of macrophage activation syndrome GO was able to resolve symptoms and led 205to complete recovery of experimental animals [11]. Pathogenetic mechanisms of sepsis and 206macrophage activation syndrome are close [21].Possibly, rapid positive efficacy of GO in our 207patients arises from its ability to decline the levels of proinflammatory cytokines, thus ameliorating 208clinical and laboratory signs of tissue damage. Of interest, incidence of grade Grade 3 or 4 sepsis $209(17 \%)$ and pneumonia (8\%) was lower than expected in relapsed AML CD33 positive patients [22]. 
210 The annoying limitation of our case report descriptions is a lack of cytokines level data and 211 morphological assessment of organ lesions.

212 Nevertheless, we suggest our clinical experience deserves attention 213of hematologists/oncologist.

\section{Conclusions}

215 We have made a successful attempt to treat three severally ill patients with organ dysfunction 216 by GO. In all of them patients, organ failure (respiratory failure and acute kidney injury) resolution 217 was achieved after a single GO infusion. Therefore, the patients became fit to the further therapy $218(" 7+3$ ", "Gemtuzumab ozogamicin+Azacitidine"). No additional hematological and 219non-hematological toxicity was noticed.

220Funding: This case reports received no external funding

221Conflicts of Interest: The authors declare no conflict of interest.

\section{References}

2231. Rabbat A, Chaoui D, Montani D, et al. Prognosis of patients with acute myeloid leukaemia admitted to 224intensive care. British Journal of Haematology. 2005;129(3):350-357. doi:10.1111/j.1365-2141.2005.05459.x.

2252. Azoulay E, Mokart D, Pène F Outcomes of Critically Ill Patients With Hematologic Malignancies: Prospective 226Multicenter Data From France and Belgium-A Groupe de Recherche Respiratoire en Re'animation 227Onco-He' matologique Study. J Clin Oncol. 2013;31(22):2810-8. doi: 10.1200/JCO.2012.47.2365

2283. Thol F, Schlenk R, Heuser M and Ganser A. How I treat refractory and early relapsed acute myeloid leukemia. 229Blood 2015;126(3):319-327. doi:10.1182/blood-2014-10-551911.

2304. Elie Azoulay, Peter Schellongowski, Michael Darmon. The Intensive Care Medicine research agenda 231on critically ill oncology and hematology patients. Intensive Care Med. 2017:1366-1382 doi: 23210.1007/s00134-017-4884-z

2335. Cardenas-Turanzas M, Ravandi-Kashani F, Cortes J et al. Expectations of Serious Adverse Events at the 234End-of-Life of Patients with Acute Myeloid Leukemia Who Receive Salvage Therapy. Clin Lymphoma 235Myeloma Leuk. 2013;13(5):579-583. doi:10.1016/j.clml.2013.03.021.

2366. Nucci M, Nouér SA, Anaissie E et al.. Distinguishing the Causes of Pulmonary Infiltrates in Patients With 237 Acute Leukemia. Clin Lymphoma Myeloma Leuk. 2015;15 Suppl:S98-103. doi:10.1016/j.clml.2015.03.007.

2387. Kovalski R, Hansen-Flaschen J, Lodato RF, Pietra GG. Localized leukemic pulmonary infiltrates. Diagnosis by 239bronchoscopy and resolution with therapy. Chest. 1990;97(3):674-678. dol:10.1378/chest.97.3.674

2408. Potenza L, Luppi M, Morselli M et al. Leukaemic pulmonary infiltrates in adult acute myeloid leukaemia: a 241high-resolution computerized tomography study. British Journal of Haematology. 2003;120(6):1058-1061. 242doi:10.1046/j.1365-2141.2003.04192.x.

2439. Halpern AB, Culakova E, Walter RB et al. Association of Risk Factors, Mortality, and Care Costs of Adults 244With Acute Myeloid Leukemia With Admission to the Intensive Care Unit. IAMA Oncol. 2017 Mar 2451;3(3):374-381. doi: 10.1001/jamaoncol.2016.4858.

24610. Patil NK, Bohannon JK, Sherwood ER. Immunotherapy: A promising approach to reverse sepsis-induced 247immunosuppression. Pharmacol Res. 2016;111:688-702. doi:10.1016/j.phrs.2016.07.019.

24811 Wunderlich M, Stockman C, Devarajan M et al. A xenograft model of macrophage activation syndrome 249amenable to anti-CD33 and anti-IL-6R treatment. JCI Insight. 2016;1(15):e88181. doi:10.1172/jci.insight.88181.

25012. Amadori S, Suciu S, Selleslag D et al. Gemtuzumab Ozogamicin Versus Best Supportive Care in Older 251Patients With Newly Diagnosed Acute Myeloid Leukemia Unsuitable for Intensive Chemotherapy: Results of 252the Randomized Phase III EORTC-GIMEMA AML-19 Trial.. I Clin Oncol. 2016 Mar 20;34(9):972-9. doi: 25310.1200/JCO.2015.64.0060.

25413.Walter RB, Medeiros BC, Gardner KM et al. Gemtuzumab ozogamicin in combination with vorinostat and 255 azacitidine in older patients with relapsed or refractory acute myeloid leukemia: a phase I/II study. 256Haematologica. 2014;99(1):54-9. doi:10.3324/haematol.2013.096545.

25714. Medeiros BC, Tanaka TN, Balaian L et al. A Phase I/II Trial of the Combination of Azacitidine and 258Gemtuzumab Ozogamicin for Treatment of Relapsed Acute Myeloid Leukemia. Clin Lymphoma Myeloma 259Leuk. 2018;18(5):346-352. doi:10.1016/j.clml.2018.02.017. 
26015. Ganzel C, Manola J, Douer D et al. Extramedullary Disease in Adult Acute Myeloid Leukemia Is Common 261 but Lacks Independent Significance: Analysis of Patients in ECOG-ACRIN Cancer Research Group Trials, 2621980-2008. J Clin Oncol. 2016;34(29):3544-3553. doi:10.1200/jco.2016.67.5892.

26316. Balaian L, Ball ED. Cytotoxic activity of gemtuzumab ozogamicin (Mylotarg) in acute myeloid leukemia 264correlates with the expression of protein kinase Syk. Leukemia. 2006;20(12):2093-2101. 265doi:10.1038/sj.leu.2404437.

26617. McNeil MJ, Parisi MT, Hijiya N et al. Clinical and Radiographic Response of Extramedullary Leukemia in 267Patients Treated With Gemtuzumab Ozogamicin. J Pediatr Hematol Oncol. 2019;41(3):e174-e176. 268doi:10.1097/MPH.0000000000001201

26918. Owonikoko T, Agha M, Balassanian R et al. Gemtuzumab therapy for isolated extramedullary AML relapse 270following allogeneic stem-cell transplant. Nature Clinical Practice. Oncology. 2007;4(8): 491-5. 271doi:10.1038/ncponc0899.

27219. Ando T, Mitani N, Matsunaga K et al. Gemtuzumab ozogamicin therapy for isolated extramedullary AML 273relapse after allogeneic hematopoietic stem-cell transplantation. Journal of Experimental Medicine. 2742010;220(2):121-6. doi:10.1620/tjem.220.121.

27520. Amadori. S. New agents for the treatment of acute myeloid leukemia: gemtuzumab ozogamicin. 276Hematology Meeting Reports. 2008;2(5):69-71.

27721. Karakike E and Giamarellos-Bourboulis E J. Macrophage Activation-Like Syndrome: A Distinct Entity 278Leading to Early Death in Sepsis. Front. Immunol. 2019;10:55. doi: 10.3389/fimmu.2019.00055.

27922. Larson RA, Sievers EL, Stadtmauer EA et al. Final report of the efficacy and safety of gemtuzumab 280ozogamicin (Mylotarg) in patients with CD33-positive acute myeloid leukemia in first recurrence. Cancer. 2812005;104(7):1442-52. doi:10.1002/cncr.21326

282

283

284

285

286

287

288

289

290 